\title{
Diagnóstico molecular da taxa de infecção natural de flebotomíneos (Psychodidae, Lutzomyia) por Leishmania sp na Amazônia maranhense
}

\author{
Molecular diagnosis of the natural infection rate due to Leishmania sp in sandflies \\ (Psychodidae, Lutzomyia) in the Amazon region of Maranhão, Brazil
}

\author{
Yrla Nívea Oliveira-Pereira ${ }^{1}$, José Manuel Macário Rebêlo ${ }^{2}$, Jorge Luiz Pinto Moraes ${ }^{2}$ \\ e Silma Regina Ferreira Pereira ${ }^{3}$
}

\begin{abstract}
RESUMO
A taxa de infecção natural de três diferentes espécies de flebotomíneos por Leishmania foi estudada usando a técnica de reação em cadeia da polimerase. Primers específicos para Leishmania foram designados para examinar se os pools de flebotomíneos estavam infectadas. Um total de 1.100 fêmeas separadas em pools de 10 indivíduos foram examinados, consistindo de 50 Lutzomyia whitmani, 43 Lutzomyia triacantha e 17 Lutzomyia choti. De todos os pools analisados, 4 de Lutzomyia whitmani estavam positivos, mas nenhum pool das duas espécies restantes estava infectado. Deste modo, uma taxa de infecção de 0,4\% foi verificada neste estudo. Esta taxa de infecção associada a estudos anteriores sugere que Lutzomyia whitmani transmite Leishmania aos mamíferos em Buriticupu, Maranhão.
\end{abstract}

Palavras-chaves: Biologia molecular. Flebotomíneos. Leishmania. Lutzomyia whitmani.

\begin{abstract}
The natural infection rate due to Leishmania was studied in three different sandfly species using the polymerase chain reaction technique. Leishmania specific primers were designed to examine whether sandfly pools were infected. In total 1,100 female sandflies separated into pools of 10 individuals, consisting of 50 pools of Lutzomyia whitmani, 43 of Lutzomyia triacantha and 17 of Lutzomyia choti, were analyzed. Among all the pools examined, four pools of Lutzomyia whitmani were positive, but none of the pools of the other two species were infected. Thus, a total infection rate of $0.4 \%$ was established in this study. A similar infection rate was found in previous studies, suggesting that Lutzomyia whitmani transmits Leishmania to mammals in Buriticupu, Maranhão.
\end{abstract} Key-words: Molecular biology. Sandflies. Leishmania. Lutzomyia whitmani.

A leishmaniose tegumentar (LT) é uma das infecções dermatológicas mais importantes, não só pela freqüência, mas principalmente pelas dificuldades terapêuticas, deformidades e sequielas que pode acarretar, por sua magnitude, transcendência e pouca vulnerabilidade às medidas de controle. No Brasil, a LT tem sido assinalada em praticamente todos os estados e vem crescendo progressivamente nos últimos 20 anos, ocorrendo surtos em todas as regiões do país. 0 Maranhão é responsável por 13\% dos casos relatados no Brasil e $47 \%$ dos da região nordeste, sendo que $47,1 \%$ dos casos são oriundos da Amazônia maranhense $\mathrm{e}^{14}$.

Os vetores responsáveis pela transmissão de LT são os flebotomíneos do gênero Lutzomyia. Estudos têm descrito a especificidade entre o parasito e o vetor responsável pela sua transmissão $0^{56}$. A identificação de uma espécie vetora e a determinação da taxa de infecção natural, sobretudo nas regiões endêmicas, é de fundamental importância na entomologia médica.

\footnotetext{
1. Curso de Pós-Graduação da Universidade Federal do Maranhão, São Luís, MA. 2. Laboratório de Entomologia e Vetores do Departamento de Patologia da Universidade Federal do Maranhão, São Luís, MA. 3. Departamento de Biologia da Universidade Federal do Maranhão, São Luís, MA.

Trabalho financiado pelo CNPq.

Endereço para correspondência: Profa. Silma Regina Ferreira Pereira. Dept ${ }^{0}$ de Biologia/UFMA. Av. dos Portugueses s/n, Campus do Bacanga, 65080-040 São Luís, MA.

Tel: 559821098543

e-mail: smartins@ufma.br

Recebido para publicação em 30/12/2004

Aceito em 8/11/2006
} 
A infecção de flebotomíneos por Leishmania era mais freqüientemente investigada através da dissecação do inseto e observação direta do parasita. Esse procedimento consome tempo e requer grande habilidade técnica, principalmente devido ao tamanho reduzido dos insetos.

0 desenvolvimento de técnicas de biologia molecular, como a reação em cadeia da polimerase (PCR), possibilitou a identificação de material genético de Leishmania, mesmo em quantidades mínimas como $50 \mathrm{fg}$ de DNA do parasita ${ }^{4}$. Trabalhos utilizando essa metodologia têm sido realizados no diagnóstico de leishmaniose ${ }^{1320}$ bem como na identificação de reservatórios animais ${ }^{8}$, detectando parasitas independentemente da abundância, estágio, local e transmissibilidade ${ }^{15}$.

Estudos sobre infecção por leishmânia em flebotomíneos, na Amazônia maranhense, ainda não foram realizados. Todavia, os inquéritos entomológicos têm mostrado claramente a presença de espécies de reconhecida importância na transmissão de leishmânias, como Lutzomyia whitmani, L. umbratilis, L. wellcomei, L. migonei e L. complexa ${ }^{18}{ }^{19}$, sendo que todas já foram encontradas infectadas por espécies de Leishmania em outras áreas biogeográficas do país $^{17}$.

É fundamental para o entendimento da cadeia de transmissão e controle da LT, a determinação das espécies de flebotomíneos vetores e o monitoramento da taxa de infecção de populações, sobretudo, em ambientes antrópicos. Assim, este trabalho tem por finalidade investigar a taxa de infecção natural das três espécies de flebotomíneos mais frequentes no ambiente peridoméstico do município de Buriticupu, MA.

\section{MATERIAL E MÉTODOS}

Área de estudo. Os flebotomíneos utilizados neste estudo foram obtidos no povoado da Sexta Vicinal, localizado no município de Buriticupu, na Amazônia maranhense, entre

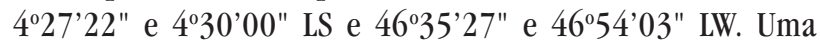
descrição detalhada dos aspectos fisiográficos da região encontra-se em Rebêlo e cols ${ }^{18} 19$.

Método de coleta dos flebotomíneos. As capturas de flebotomíneos foram realizadas das 18 às 6 horas, uma vez por mês, no período de novembro de 2003 a março de 2004. Foram instaladas seis armadilhas luminosas tipo CDC, no ambiente peridoméstico, de duas residências com casos confirmados de LT, a uma altura de $1,5 \mathrm{~m}$.

Todos os insetos capturados foram mortos em câmara refrigerada. Depois, fez-se a triagem, separando-se os flebotomíneos dos outros insetos e as fêmeas dos machos. As fêmeas foram submetidas à dissecação das espermatecas para identificação das espécies.

Seleção das espécies. Foram selecionadas para este estudo as três espécies de flebotomíneos que se mostraram mais abundantes no ambiente peridoméstico do povoado da
Sexta Vicinal: Lutzomyia choti, L. triacantha e L. whitmani, de acordo com o inquérito entomológico realizado de julho/ 2002 a agosto/2003 nesse povoado.

As fêmeas foram separadas em pools de 10 exemplares em tubos de plásticos e congeladas, para posterior extração de DNA do protozoário e condução da PCR.

Extração de DNA. Foi feita utilizando-se o protocolo descrito por Mukhopadhyay e cols ${ }^{12}$ com algumas modificações: aquecimento por 10 minutos a $95^{\circ} \mathrm{C}$ com $20 \mathrm{ml}$ de tampão STE ( $\mathrm{NaCl}$ 0,1M, Tris-HCl 10mM pH 8,0 e EDTA $1 \mathrm{mM}$ ), depois os insetos foram macerados e foi acrescentado STE até completar o volume de $50 \mathrm{ml}$. Centrifugou-se a 12.000rpm por 2 minutos e transferiu-se o sobrenadante contendo o DNA para um tubo novo.

Reação em cadeia da polimerase. A amplificação para o gênero Leishmania foi feita usando-se os primers 5'GGG (G/T)AGGGGCGTTCT (G/C)CGAA3' e 5' (G/C) (G/C) (G/C) (A/T)CTAT(A/T) TTAC CAACCCC3'9 ${ }^{\prime}$ o volume total da reação foi de $20 \mathrm{ml}$, sendo composto por $4 \mathrm{ml}$ de DNA genômico, Tampão para PCR 1X (Invitrogen); 1mM de cada primer; 1,5mM MgCl2; 200mM de cada dNTPs e 1U de Taq DNA polimerase.

A reação iniciou com uma desnaturação a $94^{\circ} \mathrm{C}$ por 5 minutos, seguida de 30 ciclos de $94^{\circ} \mathrm{C}$ por 30 segundos, $55^{\circ} \mathrm{C}$ por 30 segundos e $72^{\circ} \mathrm{C}$ por 45 segundos, tendo uma extensão final de $72^{\circ} \mathrm{C}$ por 10 minutos.

Os produtos da PCR foram separados em gel de agarose a $2 \%$, e as bandas foram visualizadas sob luz UV após coloração com brometo de etídeo. Como controle positivo foi utilizado DNA de Leishmania braziliensis e como o controle negativo, DNA de machos de flebotomíneos capturados nas coletas. A contaminação por DNA exógeno foi evitada através de cuidadoso manuseio de pipetas e reagentes. As amostras positivas foram confirmadas pela repetição da reação. A amplificação produziu fragmentos de $120 \mathrm{pb}$ para o gênero Leishmania.

A taxa de infecção mínima foi calculada considerando-se todas as amostras com 10 indivíduos e apenas um flebotomíneo positivo para Leishmania por amostra. A taxa de infecção mínima para espécie foi obtida considerando-se todos os pools da espécie com 10 flebotomíneos e apenas um infectado por amostra.

\section{RESULTADOS}

Neste estudo, foram analisadas 1.100 fêmeas de flebotomíneos distribuídas nas espécies $L$. whitmani $(500$ espécimes), L. triacantha (430) e L choti (170), por serem as espécies mais abundantes na área. As fêmeas foram separadas em pools de 10 exemplares, sendo 50 pools de L. whitmani $(45,5 \%), 43$ de $L$. triacantha $(39,1 \%)$ e 17 de L. choti $(15,4 \%)$.

Quatro pools de L. whitmani apresentaram produtos de amplificação de 120pb para o gênero Leishmania (Figura 1), enquanto as amostras de $L$. triacantha e $L$. choti mostraram-se 


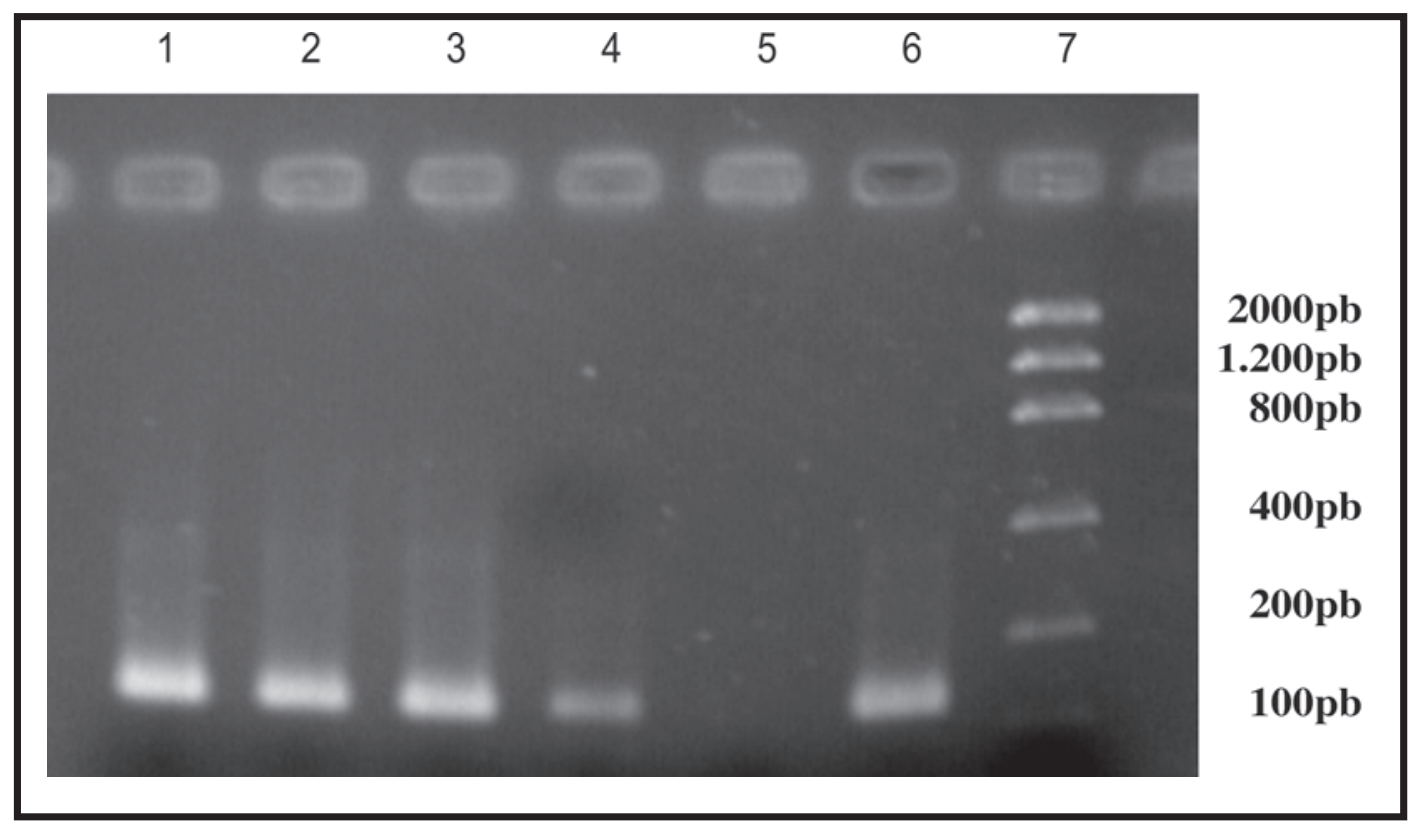

Figura 1 - Produtos de amplificação para o gênero Leishmania realizada em fêmeas de flebotomíneos. Linhas: 1, 2, 3 e 4. Fêmeas positivas de Lutzomyia whitmani, 5. Controle negativo (DNA de machos de flebotomíneos), 6. Controle positivo (DNA de Leishmania braziliensis), 7. Marcador de peso molecular.

negativas. A taxa de infecção mínima para a espécie L. whitmani foi de $0,8 \%$ e para o total de indivíduos das três espécies foi de $0,4 \%$.

Todas as amostras tiveram suas reações de PCR e eletroforese repetidas para confirmação do resultado. Procedeu-se também ao teste de inibição para assegurar possíveis falhas na técnica. Esse teste foi realizado em 20 amostras cuja PCR foi negativa, sendo 7 de $L$. whitmani, 8 de $L$. triacantha e 5 de $L$. choti, e consistia em repetir a reação nas mesmas condições, exceto pela adição de $1 \mathrm{ml}$ de DNA de Leishmania. Após esta última reação, todas as amostras testadas positivaram, mostrando que não ocorreu amplificação inicialmente devido à ausência de DNA de Leishmania.

\section{DISCUSSÃo}

A taxa de infecção natural dos flebotomíneos, utilizando PCR, encontrada neste estudo, foi semelhante à observada por Miranda cols ${ }^{11}$ em uma área endêmica de LT na Bahia. Esta taxa é suficiente para a manutenção da endemicidade da infecção. Vexenat e cols ${ }^{22}$ relatam que a investigação da infecção em flebotomíneos capturados de forma não direcionada, mostra uma taxa ainda mais baixa ou mesmo nula.

Quanto aos métodos de diagnósticos empregados, a PCR mostrou-se mais específica e sensível do que a dissecação dos flebotomíneos ${ }^{2}$ e outros métodos convencionais de diagnóstico em pacientes ${ }^{1320}$. Isto ocorre porque esta técnica permite a detecção de 0,6 parasita por tubo de reaçã $0^{4}$.

Dentre as três espécies selecionadas para este estudo, levando-se em consideração a densidade das mesmas na localidade de Sexta Vicinal, somente $L$. whitmani é reconhecidamente vetora de LT no Brasil, enquanto para as outras duas não existe nenhum relato sobre exemplares naturalmente infectados. Assim, este estudo mostra a capacidade da população de $L$. whitmani de Buriticupu de se infectar com Leishmania, indicando o seu provável papel como vetor de LT neste município.

Convém ressaltar que a LT constitui um grande problema de saúde no município de Buriticupu pois, desde a década de 70, quando era uma área de colonização agropastoril, temse registrado surtos epidêmicos da doença. 0 primeiro, com 300 casos, foi registrado por Silva cols ${ }^{21}$, coincidindo com 0 período em que havia recebido um grande contingente populacional do interior do próprio estado e de outros estados do nordeste.

A partir de 1997, com sua emancipação, Buriticupu registrou os mais altos coeficientes de detecção anual de LT do Maranhão: 688,21 (1997), 442,44 (1998), 331,81 (1999), 883,18 (2000), 678,65 (2001) e 721,67 (2002). No ano de 2003, foram 242 casos novos, e de janeiro até maio de 2004 já eram 123 casos.

A determinação das leishmânias, por meio de análise isoenzimática, de pacientes de Buriticupu, revelou a presença de espécies do complexo braziliensis, sendo Leishmania shawi a espécie mais freqüente ${ }^{3}$.

Em todas as localidades do município de Buriticupu onde os flebotomíneos foram estudados, $L$. whitmani sempre aparece como sendo uma das espécies mais frequientes, tanto no ambiente silvestre quanto no doméstico, daí a suspeita deste flebotomíneo ser o vetor principal da LT nessa região do Estado ${ }^{18} 19$.

É conhecido o papel de L. Whitmani como vetor de Leishmania do complexo braziliensis, mas estudos de DNA 
mitocondrial de diferentes populações deste flebotomíneo mostraram que, no Brasil, existem três linhagens diferentes desta espécie. A linhagem amazônica, à qual pertence a população de Buriticupu, transmite Le. shawi e tem como reservatórios, primatas, quirópteros, desdentados e carnívoros ${ }^{5}$; diferindo, portanto, das outras linhagens que transmitem Le. braziliensis ${ }^{17}$.

Por outro lado, a população de L. whitmani da Amazônia paraense não mostra uma forte tendência antropofílica, tampouco sinantrópica ${ }^{16}$, e segundo Lainson cols ${ }^{7}$, os efeitos da destruição da floresta primária sobre esta população seriam drásticos, de tal maneira que o ciclo natural de Le. shawi e L. whitmani seria interrompido.

Em contraposição a isto, em Buriticupu, observa-se a existência de um duplo perfil epidemiológico, onde os altos coeficientes de infecção de IT humana são mantidos por casos oriundos de focos antigos, e por surtos epidêmicos associados ao desflorestamento da mata, decorrentes de fatores como 0 acelerado processo de expansão das fronteiras agrícolas, construção de estradas, e outras atividades humanas que contribuem sobremaneira para o aumento no número de $\operatorname{casos}^{10}$. Ambos os perfis, são concordantes com o padrão de distribuição de $L$. Whitmani na área ${ }^{18}{ }^{19}$, levando-nos a acreditar tratar-se de um vetor eclético que pode transmitir a infecção tanto no domicílio humano quanto na floresta.

De qualquer modo, os resultados aqui obtidos mostram que a infecção circula nos flebotomíneos que se encontram no ambiente peridoméstico. Com as ferramentas moleculares hoje disponíveis, estudos sobre a natureza espécie-específica da leishmânia podem ser conduzidos no sentido de caracterizar, no futuro próximo, a espécie de leishmânia transmitida por $L$. whitmani nessa região. Além disso, é necessária a continuação deste estudo para que se determine a presença ou não de infecção em outras espécies de flebotomíneos. Outros estudos precisam ser realizados em outras áreas do estado para que se observe se existe relação entre a taxa de infecção e o número de casos de doença.

\section{REFERÊNCIAS BIBLIOGRÁFICAS}

1. Azevedo ACR, Rangel EF, Costa ME, David J, Vasconcelos AW, Lopes UG. Natural infection of Lutzomyia (Nyssomyia) whitmani (Antunes \& Coutinho, 1939) by Leishmania of the braziliensis complex in Baturité, Ceará State. Memórias do Instituto Oswaldo Cruz 85: 251, 1990.

2. Feliciangeli MD, Reyes RM, Limongi JE. Natural infection of Lutzomyia ovallesi (Diptera: Psychodidae) with parasites of the Leishmania braziliensis complex in a restricted focus of cutaneous leishmaniasis in northern Venezuela. Memórias do Instituto Oswaldo Cruz 83: 393-394, 1988.

3. Figueredo FV, Cunha AK, Gama MEA, Costa JML. Leishmaniose Tegumentar Americana (LTA) em área endêmica do estado do Maranhão. In: Resumos do XXXIII Congresso da Sociedade Brasileira de Medicina Tropical p.43, 1997.

4. Fu G, Perona-Wright G, Barker DC. Leishmania braziliensis: characterisation of a complex specific subtelomeric repeat sequence and its use in the detection of parasites. Experimental Parasitology 90: 236-243, 1998.

5. Grimaldi G, Thesh RB. Leishmaniasis of the New World: current concepts and implications for future research. Clinical Microbiology Reviews 6: 230-250, 1993
6. Lainson R, Shaw JJ. Epidemiology and ecology of leishmaniasis in Latin America. Nature 273: 595-599, 1987.

7. Lainson R, Shaw JJ, Silveira FT, Souza AA, Braga RR, Ishikawa EAY. The dermal leishmaniasis of Brazil, with special reference to the ecoepidemiology of the disease in Amazonia. Memórias Instituto Oswaldo Cruz 89: 435-443, 1994.

8. Llanos-Cuentas EA, Roncal N, Villaseca P, Paz L, Ogusuku E, Pérez JE, Cáceres A, Davies CR. Natural infections of Leishmania peruviana in animals in the Peruvian Andes. Transactions of the Royal Society of Tropical Medicine and Hygiene 93: 15-20, 1999.

9. Marques MJ, Volpini AC, Genaro 0, Mayrink W, Romanha AJ. Simple form preservation and Leishmania DNA extraction form human lesions for diagnosis of american cutaneous leishmaniasis via polymerase chain reaction. American Journal of Tropical Medicine and Hygiene 65: $902-$ 906, 2001.

10. Martins LM, Rebêlo JMM, Santos MCFV, Costa JML, Silva AR, Ferreira LA. Ecoepidemiologia da leishmaniose tegumentar no Município de Buriticupu, Amazônia do Maranhão, Brasil, 1996 a 1998. Cadernos de Saúde Pública 20:735-743, 2004.

11. Miranda JC, Reis E, Schriefer A, Gonçalves M, Reis MG, Carvalho L, Fernandes 0, Barral-Neto M, Barral A. Frequency of infection of Lutzomyia phlebotomines with Leishmania braziliensis in a Brazilian endemic area as assessed by pinpoint capture and polymerase chain reaction. Memórias do Instituto Oswaldo Cruz 97: 185-188, 2002.

12. Mukhopadhyay J, Ghosh K, Braig HR. Identification of cutaneous leishmaniasis vectors, Phlebotomus papatasi e P. duboscqi using random amplified polymorphic DNA. Acta Tropica 76: 277-283, 2000.

13. Oliveira CI, Báfica A, Oliveira F, Favali CB, Correa T, Freitas LAR, Nascimento E, Costa JM, Barral A. Clinical utility of polymerase chain reaction - based detection of Leishmania in the diagnosis of American cutaneous leishmaniasis. Clinical Infections Diseases 37: 149-153, 2003.

14. Oliveira ML. Relatório sobre o Programa de Controle de Leishmaniose Tegumentar Americana (LTA). Divisão de Dermatologia Sanitária da Fundação Nacional de Saúde. Brasília, 1996.

15. Perez JE, Ogusuku E, Inga R, Lopez M, Monje J, Paz L, Nieto E, Arevalo J, Guerra H. Natural Leishmania infection of Lutzomyia spp in Peru. Transactions of the Royal Society of Tropical Medicine and Hygiene 88: 161-164, 1994.

16. Rangel EF, Lainson R, Souza AA, Ready P, Azevedo ACR. Variation between geographical populations of Lutzomyia (Nyssomyia) whitmani (Antunes \& Coutinho, 1939) sensu lato (Diptera: Psychodidae: Phlebotominae) in Brazil. Memórias do Instituto Oswaldo Cruz 91: 43-50, 1996.

17. Ready PD, Souza AA, Rebêlo JMM, Day JC, Silveira FT, Campbell-Lendrum D, Davies CR, Costa JML. Phylogenetic species and domesticity of Lutzomyia whitmani at the south-east boundary of Amazonian Brazil. Transactions of the Royal Society of Tropical Medicine and Hygiene 92: 159-160, 1998.

19. Rebêlo JMM, Oliveira ST, Silva FS. Flebotomíneos da Amazônia maranhense. IV. Riqueza e abundância relativa das espécies em área de colonização antiga. Entomologia y Vectores 7: 61-72, 2000b.

18. Rebêlo JMM, Oliveira ST, Silva FS, Costa JML, Ferreira LA, Silva AR Phlebotominae (Diptera: Psychodidae) de Lagoas, município de Buriticupu, Amazônia Maranhense. I. Riqueza e abundância relativa das espécies em área de colonização recente. Revista da Sociedade Brasileira de Medicina Tropical 33: 11-19, 2000a.

20. Rodrigues EHG, Brito MEF, Mendonça MG, Werkhäuser RP, Coutinho EM, Souza WV, Albuquerque MFPM, Jardim ML, Abath FGC. Evaluation of PCR for diagnosis of american cutaneous leishmaniasis in an area of endemicity in northeastern Brazil. Journal of Clinical Microbiology 40: 3572-3576, 2002.

21. Silva AR, Martins G, Melo JEM, Araújo JP, Mendes MG. Surto epidêmico de leishmaniose tegumentar americana na colonização agrícola de Buriticupu (MA). Revista do Instituto de Medicina Tropical 21: 45-50, 1979.

22. Vexenat JA, Barretto AC, Cuba CC, Marsden PD. Epidemiological characteristics of American cutaneous leishmaniasis in an endemic region of the State of Bahia. III. Phlebotomine fauna. Memórias do Instituto Oswaldo Cruz 81: 293-301, 1986. 